\title{
Was Euro the magic wand for economic growth? An analysis of the real benefits of Euro adoption for the New Member States
}

\author{
Ana-Maria HOLOBIUC \\ Bucharest University of Economic Studies, Bucharest, Romania \\ anamaria_holobiuc@yahoo.com \\ Bogdan MIHAI \\ Babeş-Bolyai University, Cluj Napoca, Romania \\ bogdanmmihai@gmail.com
}

\begin{abstract}
At the beginning of the $21^{\text {st }}$ century, the European single currency has been considered a guarantor of prosperity and welfare for the countries that were able to meet the nominal convergence criteria. Starting with Slovenia, a number of five Center and Eastern European Countries joined the Economic and Monetary Union, aiming to achieve the economic prosperity of the Western countries. The concept of economic convergence has been popularized through the economic growth literature during the last century and has become more and more debated with the deepening and expansion of the European Union. The main purpose of this paper has been to evaluate whether there is any hard evidence attesting that Euro adoption accelerated the economic development and created a significant advantage for the New Member States that opted for the single currency, as compared with their peer countries. In this respect, we have studied a panel of New Member States that joined the European Union in 2004 and 2007, comprising both Euro and Non-Euro countries, and we concluded that the single currency do not necessarily guarantee higher growth rates. Moreover, we revealed that the Euro New Member States were more affected by the economic and financial crisis than their Non-Euro peers. We have also shown that there are significant discrepancies between the early adopters of the Euro and the countries that joined the Eurozone after 2004 in terms of convergence and that the differences between the two groups have expanded in the last years. Last and not the least, in order to test our hypotheses, we have compared two sister-countries: Slovakia that joined the Eurozone in 2009 and Czech Republic that has not taken until now the decision to adopt the Euro. In this respect, our results suggest that both countries had good economic performances, and for some periods Czech Republic outperformed Slovakia, mainly in terms of GDP per capita and Foreign Direct Investment. Therefore, we concluded that the single currency has not significantly enhanced the economic performances in the case of the New Member States.
\end{abstract}

\section{Keywords: European Union, New Member States, Real Convergence, Slovakia, Czech Republic}

\section{Introduction}

Reputed theoreticians and policy makers have defined over time the European integration project as a success story and a guarantor of regional prosperity and welfare. After the collapse of communism in Central and Eastern Europe, countries have taken steps towards establishing a market economy and rule of law, being attracted by the performances of Western European countries and the advantages of regional integration. Consequently, at the beginning of the $21^{\text {st }}$ century, 13 European countries have chosen to be part of the EU aiming to improve their economic and social performances. Moreover, some of the New Member States (NMS) - Slovenia (2007), Cyprus (2008), Malta (2008), Slovakia (2009), Estonia (2011), Latvia (2014) and Lithuania (2015) - joined the Eurozone soon, being attracted by the advantages of the Monetary Union. The purpose of this paper is to study if the decision of 
adopting the single currency had a significant positive impact of the economic performances of the NMS.

\section{Literature review}

\section{The concept of real convergence}

Real convergence has been one of the key promises of the European Union and is reffering to the poor economies catching-up with the level of developed ones. The concept has been popularized in the second half of the $20^{\text {th }}$ century, and has become more and more challenging with the establishment and expansion of the European Union. Theoreticians have made a distinction between two main types of convergence: nominal and real. Nominal convergence takes into consideration a specific set of economic parameters, initially defined in the Maastricht Treaty as prerequisites for Euro adoption (therefore also referred to as "the Maastricht criteria"), such as inflation, government finance, exchange rate and long-term interest rates. In contrast, real convergence is focused on indicators measuring living standards, especially income per capita, studying if the disparities between Euro and NonEuro countries norrow up in time. Furthermore, with the deepening of the European Economic and Monetary Union, reaserchers and experts identified other types of convergence, such as: cyclical, structural, legal and institutional. Althought all this concepts are relevant for the study of the convergence within the EU, this paper will illustrate only the evolution in terms on real convergence.

From the perspective of Baumol et al. (1994), convergence is taken into consideration in the evaluation of the well being of economies. Furthurmore, this concept suggests that the catching up process entail a decrease in the absolute and relative levels of poverty. According to Sollow (1956), a proeminent exponent of the neoclassical theory, economic integration will bring about convergence, taking into consideration its positive impact on the free mobility of production factors. From Solow's perspective, the different growth rates between countries derive from holding a different volume of phisycal capital, the countries positioning themselfs in different phases of growth. In consequence, Solow's theory suggests that countries will achieve in long run the same level of development (state of ecquilibrium). In response to the waknesses of Solow's theory, a new theory (Romer, 1986; Lucas, 1988) has been developed, which includes increasing returns and technological changes within the production function (Corrado et al. 2005). These studies take into consideration the impact of a higher profitability of production factors or innovation (Del Hoyo et al., 2017). However, another study suggests that economic integration promotes geographic disparities as the production factor will be abundant in the rich countries, contributing to the amplification of gaps between regions (Beyaert \& Camacho, 2008).

Researchers such as Mankiw et al. (1992) expanded the Solow's model by including the acumulation of human capital, population growth and physical capital, concluding that these determinants explain the cross-sectional differences in the Solow model. From the perspective of Mankiw et al., the model proposed by Solow do not show convergence, but the conditional convergene.

Analysts such as Baumol (1986), Wolff (1991), Barro (1991), Barro \& Sala-i-Martin $(1991,1992)$ have studied the cross-sectional relationship between the initial GDP growth and the subsequent growth rate. A negative correlation suggests the existence of convergence, showing that on average, countries with lower initial incomes grow faster than the rich ones.

DOI: 10.2478/picbe-2019-0074, pp. 840-853, ISSN 2558-9652| Proceedings of the $13^{\text {th }}$ International Conference on Business Excellence 2019 
More recently, Evans \& Karras (1996), have empirically test the existence of convergence between 48 states from US, reaveling a process of convergence between them, a conclusion reached by the neolastical growth models before.

In oder to empirically study the real convergence, experts have used the concepts of $\beta$ and $\sigma$-convergence that were brought to the fore-front by Barro \& Sala-i-Martin (1992). $\beta$ convergence stems from the neo-clasical growth model and shows a negative relationship between GDP per capita growth and the initial income. In consequence, this concept shows that the poorer countries will grow faster than the developed ones. In contrast, the concept of $\sigma$-convergence shows that the dispersion of income between coutries reduces over time.

\section{The New Member States and the Euro}

With the expansion and deepending of the European integration project, theoreticians gave more and more attention to the impact of the Euro adoption on the economic performances of the EU Member States. After the establishment and the subsequent stages of expansion of the Eurozone, some analysts demonstrated the existence of a paradox: although the early adopters were expecting that the single currency will enhance the economic growth and real convergence, this desiderate was not accomplished so far (del Hoyo et. al., 2007; Franks et al., 2010; auf dem Brinke, 2015; Gros, 2018). According to Franks et al. (2010), after the adoption of the Maastricht Treaty, the initial countries that joined the Eurozone experienced a slowdown in terms of the income convergence, and even the opposite process: divergence. However, del Hoyo et al. (2007) and Franks et al. (2010) admit the existence of a temporary process of real of convergence before the crisis between the early adopters of the Euro.

Furthermore, the ECB experts (del Hoyo et. al, 2007) demonstrated that the Euro adoption has not been a defining factor in obtaining better economic performance and enhancing the real convergence mainly for the CEE countries. In contrast, the authors suggested that the transition to the market economy and the effort to incorporate in the acquis communautaire have played a most important role than the adoption of the Euro. Like other authors, Franks et al. (2010) demonstrated that the NMS have a significant higher pace of convergence than the Old Member States (OMS). However, Franks (2010) emphasized that in spite of the weaker real convergence performances, this indicator has been higher in the case of the Euro countries than in the EU28.

As far as the regional inequalities are concerned, Artelaris et al. (2010) empirically demonstrated that they significant increased after the collapse of communism regime in Central and Eastern Europe, reaching the level of the OMS. Furthermore, the authors identified the existence of convergence clubs between the regions of the NMS. In addition to this, van Loon (2018) illustrated the existence of a convergence club within the EU, which didn't occur as a result of the Euro adoption. Moreover, from the perspective of van Loon, there was no convergence between the EU countries during 40 years (1970-2010). As far as the income is concerned, it seems that a convergence process existed before the crisis between the Eastern European countries that joined the Eurozone. However, in the case of some old Euro states, the convergence process wasn't identified (van Loon, 2018).

Finally, some authors suggested that Eurozone need reliable convergence criteria for assessing the sources of imbalances. These imbalances are deriving from the absence of the price convergence, the lack of convergence in the area of competiveness and the unsustainable external balances (auf dem Brinke, 2015). 


\section{Methodology}

In this paper, we analyze the GDP per capita of EU Member States based on purchasing power parities. This indicator is used for comparisons between the living standards of countries at a given point in time. We also have used statistical measures such as the standard deviation in order to test how close are the individual economic performances of the Euro NMS (except Cyprus and Malta) and Non-Euro NMS from the mean value. We also have brought to the forefront the coefficient of variation which shows the relative variability between the NMS and the Eurozone's average. These two indicators have been used to illustrate the degree of convergence/divergence inside three main groups of countries: Euro NMS, Non-Euro NMS and the Euro area (the initial 12 countries). Beside the GDP per capita, we also compared the dynamic of other two economic indicators for Euro and Non-Euro countries that serve as signals of competitiveness and productivity, namely the export growth and stock of foreign direct investment per capita.

\section{Results and discussions}

In order to study if the accession to the Eurozone acted as a catalyst for economic growth in the case of the NMS, we have studied the evolution of GDP per capita during 2000-2007, calculating for every country the average of the period. In this respect, Figure 1 shows that during 2000-2017, the most impressive economic growth was reached by Slovenia (with an average GDP per capita of 84 PPS). Estonia recorded a GDP per capita representing $64 \%$ of the EU average, while Lithuania of $54 \%$. As far as Slovakia is concerned, the first NMS that adopted the Euro in 2009, it registered an average GDP per capita of 67 PPS. Latvia recorded the smallest GDP per capita within the Euro NMS, with an average of 54 PPS.

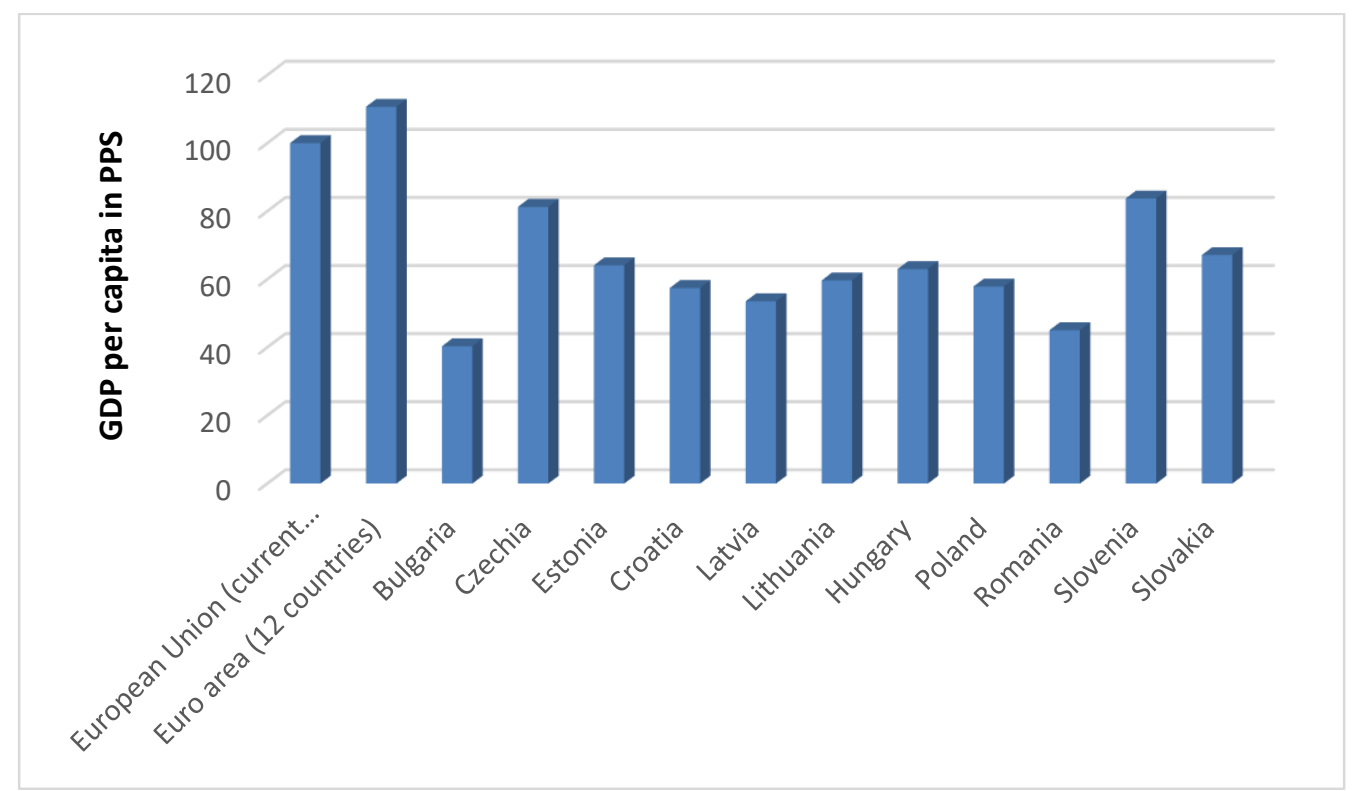

Figure 1. GDP per capita in PPS of Euro NMS

Source: Authors' processing based on data provided by Eurostat

Figure 2 illustrates the average of GDP per capita in the case of the Non-Euro NMS. As in the case of the Euro NMS, there were significant differences in the values in the case of the 
Non-Euro NMS. For example, Bulgaria had the smallest GDP per capita average for the period 2000-2017 representing 40 PPS. Furthermore, Romania, that in 2000 had a GDP per capita of 28 PPS, recorded an average value until 2017 of 45 PPS. Poland and Croatia registered close values: 58 PPS and respectively, 57 PPS. Finally, Hungary had an average in terms of GDP per capita of 58 PPS, while Czech Republic of 81 PPS. It is worth mentioning that the Non-Euro NMS, were less affected or at all by the economic and financial crisis, registering over the period significant performances in terms of GDP per capita.

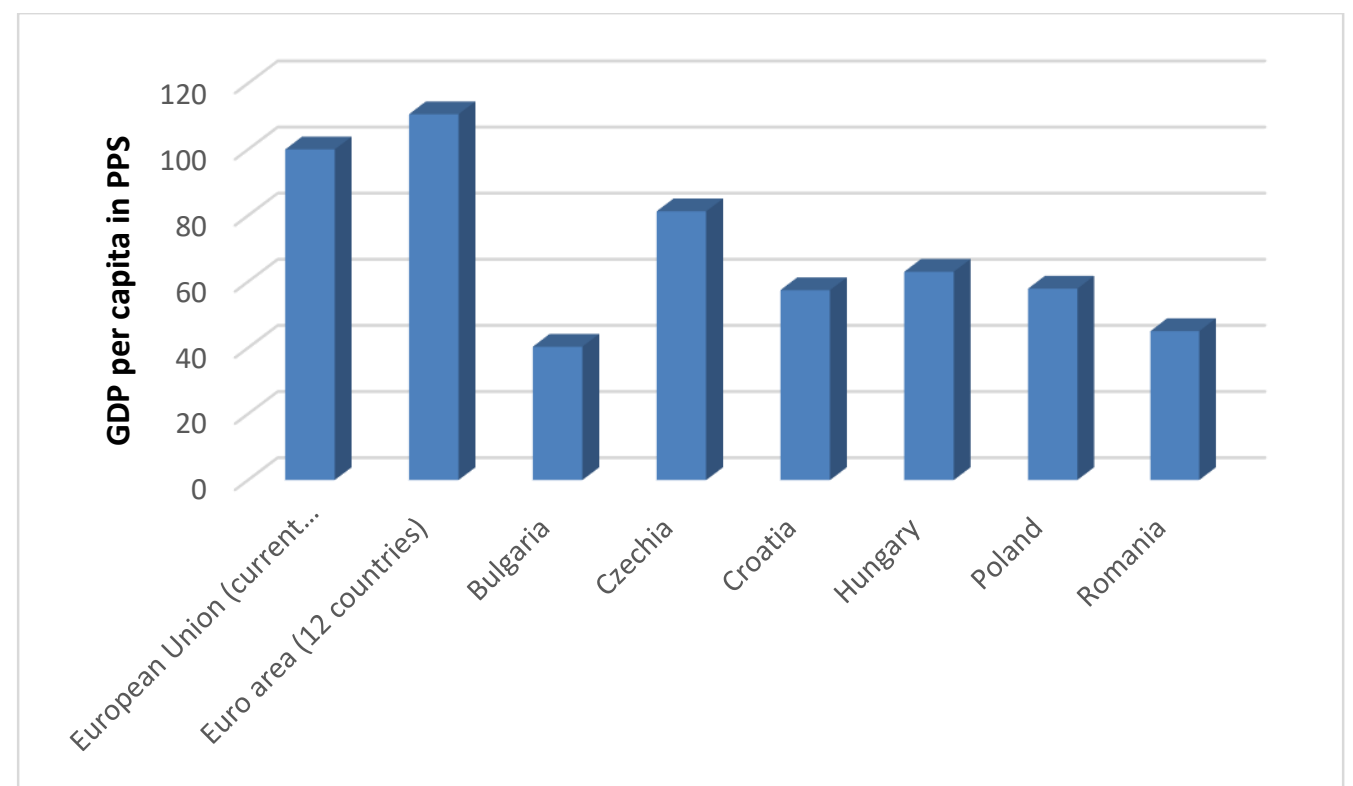

Figure 2. GDP per capita in PPS of Non-Euro NMS

Source: Authors' processing based on data provided by Eurostat

In order to test the degree of convergence between the NMS and to study if the Euro adoption was a defining factor for catching up, we have calculated the standard deviation and the coefficient of variation for Euro NMS, Non-Euro NMS and Euro area (12 countries). In this respect, Figure 3 shows the evolution of the standard deviation for these three categories between 2000 and 2017. The standard deviation of the Euro NMS decreased from 18.4 (2000) to 6.5 (2007). However, entering the Eurozone was not the only factor that determined the reduction of disparities, as this trend existed before these countries even joined the EU. As far as the Non-Euro NMS are concerned, the standard deviation decreased over time, but overall the period was characterized by erratic evolution.

As far as the initial adopters of the Euro, it seems that the standard deviation decreased until 2006, and then the discrepancies between the countries started to increase. In consequence, the standard deviation reached the value of 21 in 2017, while in 2000 was 19.1.

Overall, the Euro NMS registered by far a better performance than the early adopters of the single currency and by the Non-Euro NMS. 


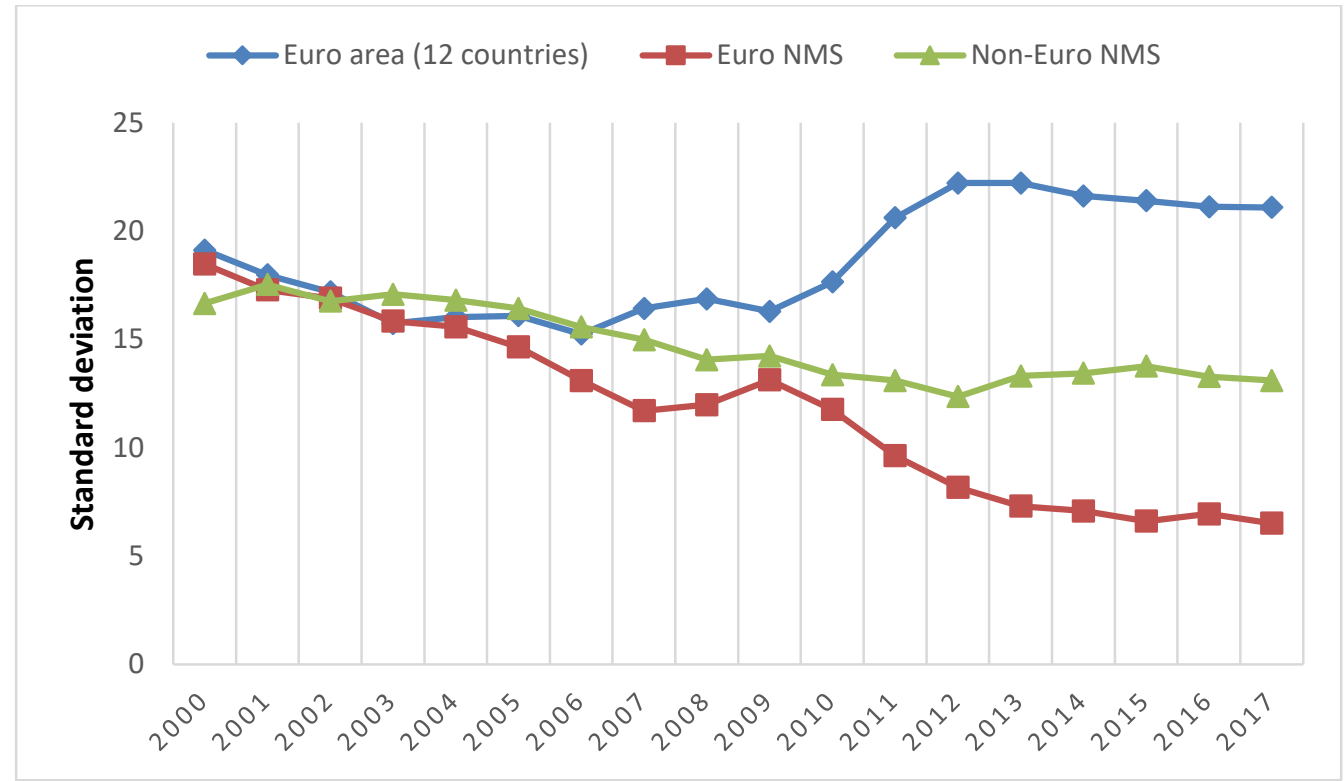

Figure 3. Standard deviation of NMS

Source: Authors' calculations

Figure 4 illustrates the coefficient of variation for Euro NMS, Non-Euro NMS and Euro area. The dispersion of GDP per capita of Euro NMS decreased from 38 (2000) to 8.4 (2017), fact that reveal a high degree of convergence in this group of countries. However, the Euro NMS were significant affected by the economic and financial crisis, but after 2010 the countries succeeded to reduce the discrepancies between them. As far as the Non-Euro NMS are concerned, the coefficient of variation decreased over the period from 36.7 to 19.6, fact that reveals that the dispersion within this group of countries is diminishing gradually.

In the case of the Euro area (12 countries) it seems that the dispersion increased over the period, from 16.8 (2000) and 20.2 (2017). Consequently, it is a significant higher degree of convergence between the Euro NMS than the early adopters. Moreover, the Non-Euro NMS succeeded to reduce the disparities between them, the coefficient of variation being under the value of the Euro area countries. 


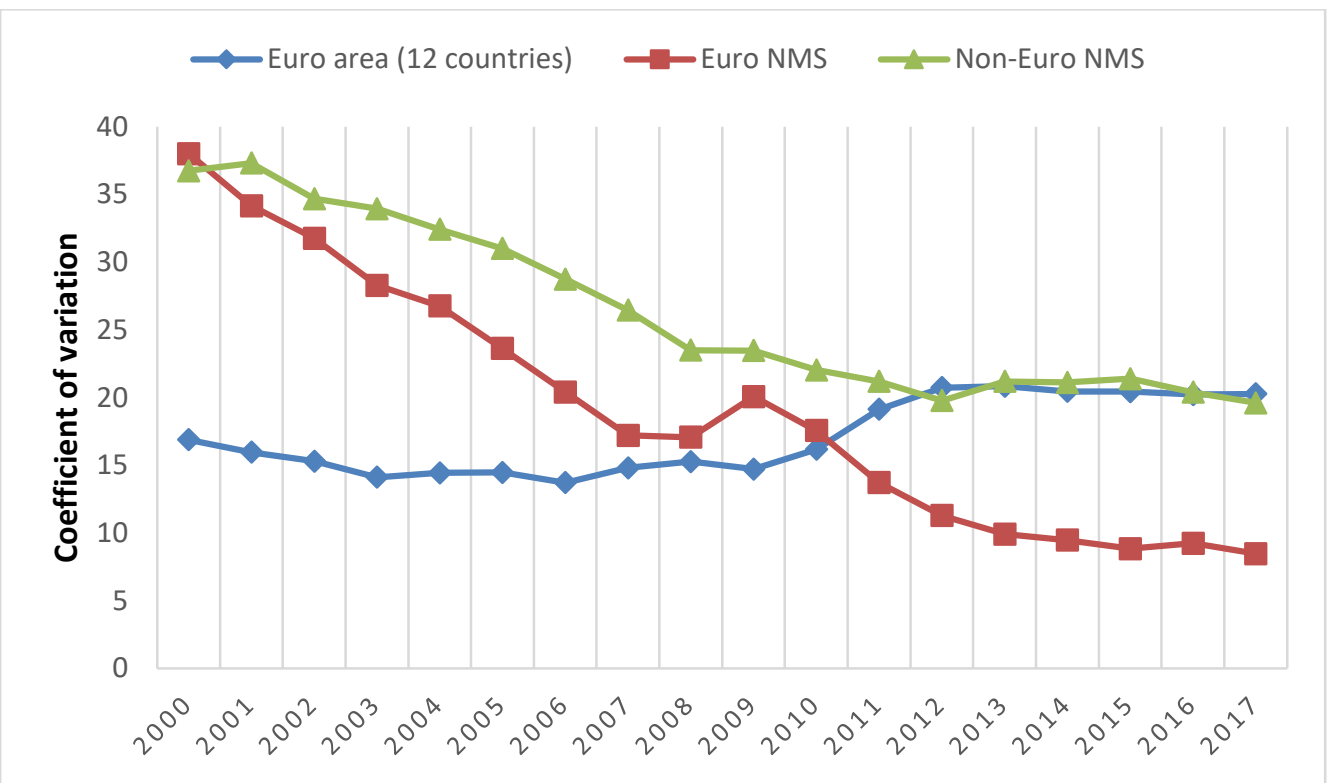

PICBE | 846

Figure 4. Coefficient of variation of NMS

Source: Authors' calculations

In 2009, Slovakia adopted Euro, while her sister-country, the Czech Republic continued to express doubtfulness regarding such an option. Therefore, we believe that a comparison between the two countries in terms of economic developments post 2009 could bring more light on the real benefits of the euro adoption. In 2006, GDP per capita in PPS in Czech Republic was $79 \%$ of the EU average, while in Slovakia was $63 \%$.

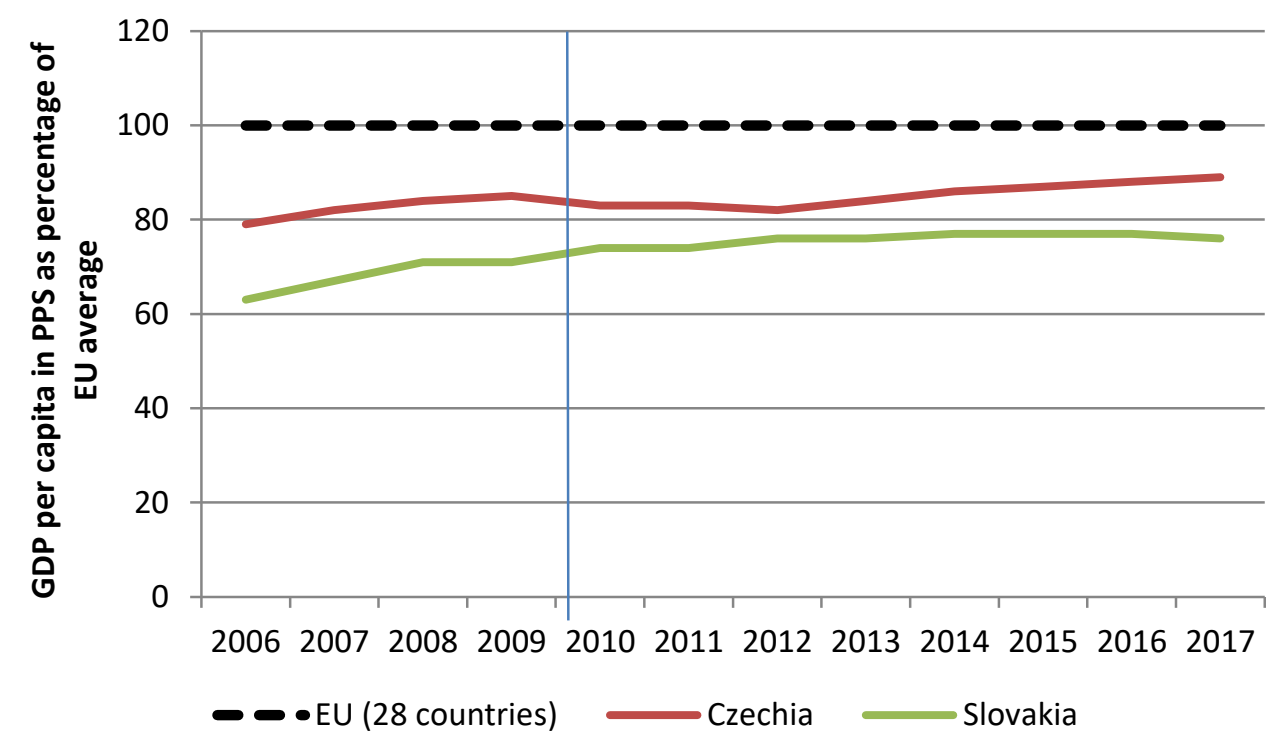

Figure 5. Czech Republic vs. Slovakia - GDP per capita as percentage of EU average Source: Authors' calculations based on data provided by Eurostat

Eleven years later in 2017, this economic gap has been narrowed from 16 percentage points to 13 percentage points, Czech Republic displaying a GDP per capita of $89 \%$ of EU 
average and Slovakia of $76 \%$. Figure 5 shows that gap has been reduced mainly due to the recession in Czech Republic in 2010-2012. Slovakia succeeded to tackle better the global financial crisis and avoid an economic "hard landing", but the catching-up process slowed down after 2012, as showed by Figure 6. For instance, while in the period 2006-2010, Slovakia's GDP was getting closer to the to the EU average with a pace of 2.2 percentage points per year, later in 2011-2017, the pace was only 0.3 percentage points per year.

PICBE $\mid 847$

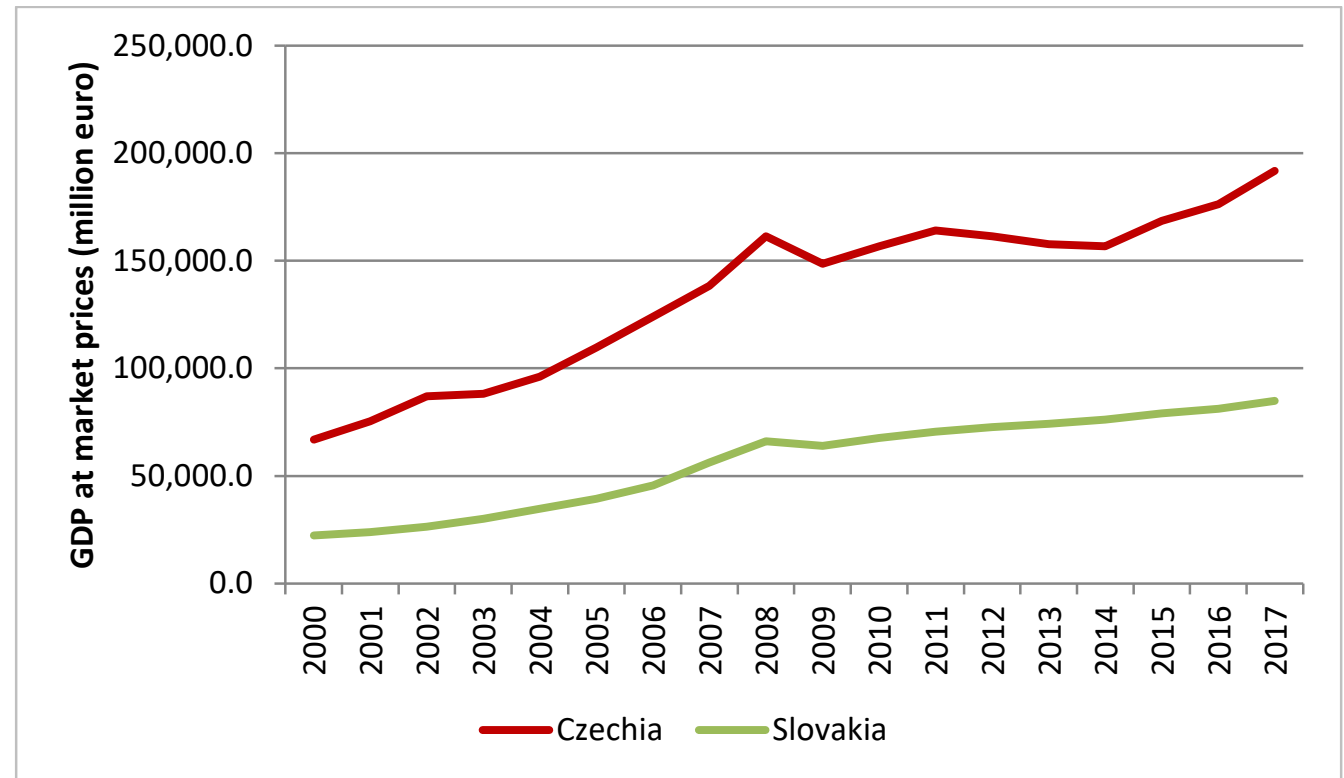

Figure 6. Czech Republic vs. Slovakia - Nominal GDP at market prices

Source: Authors' calculations based on data provided by Eurostat

This trend was also followed by the total exports of goods and services: during 20072010, the average increase of export in Slovakia was around 5.5\% per year and only $2.2 \%$ in Czech Republic; from 2011 to 2017 the pace in Slovakia was reduced dramatically to $-0.1 \%$ per year, while in Czech Republic was $0.2 \%$ per year. 


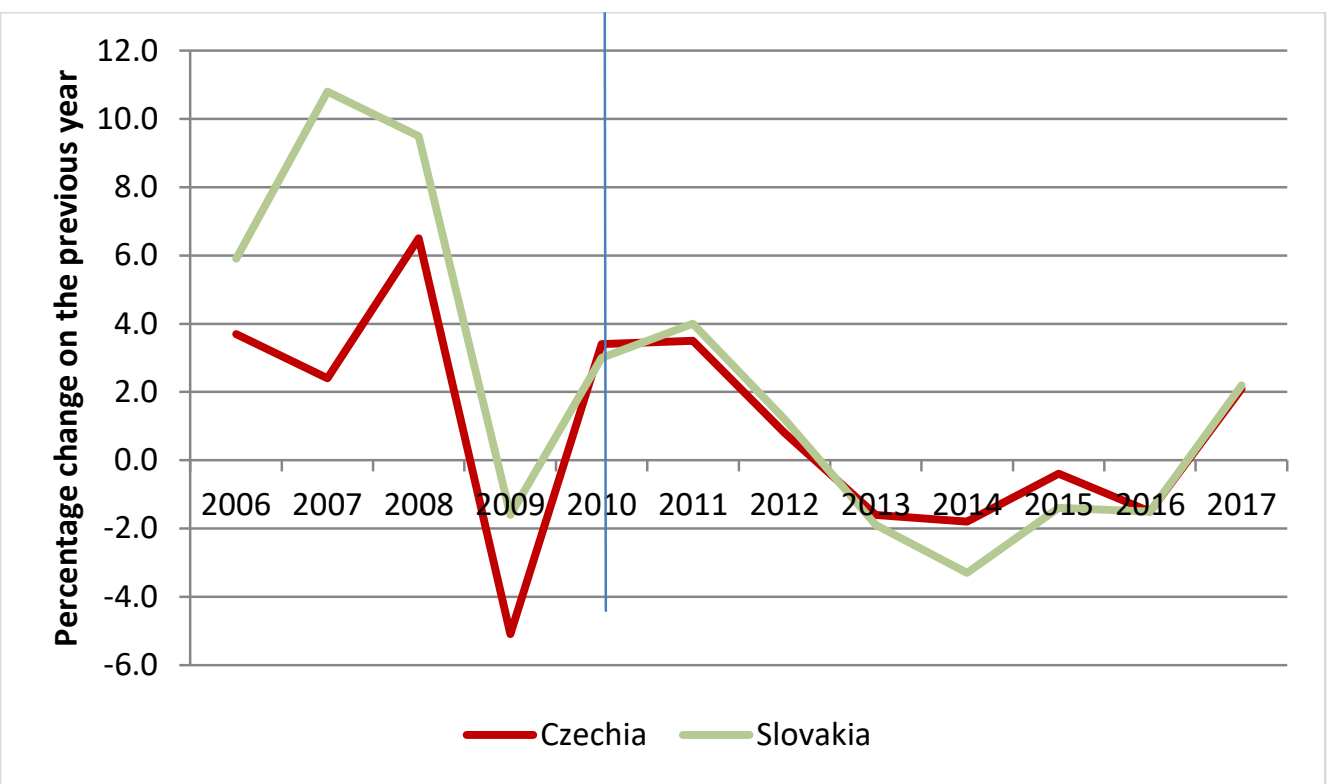

Figure 7. Czech Republic vs. Slovakia - Export growth

Source: Authors' calculations based on data provided by Eurostat

We have also examined the evolution of foreign direct investments (FDI) for the two sister countries, as this indicator play a significant role in measuring investor confidence in the economy. While in 2000, the stock of FDI was US dollar 2103 per capita in Czech Republic, in Slovakia it was only USD 1291 per capita, therefore a difference of 63\%. In the following decade, this gap has been gradually narrowed to $16 \%$ in 2008 , when it started increasing again to $53 \%$ in 2017 . Based on this evolution, we could conclude that euro adoption did not stimulate the inflow of FDI, but on the contrary.

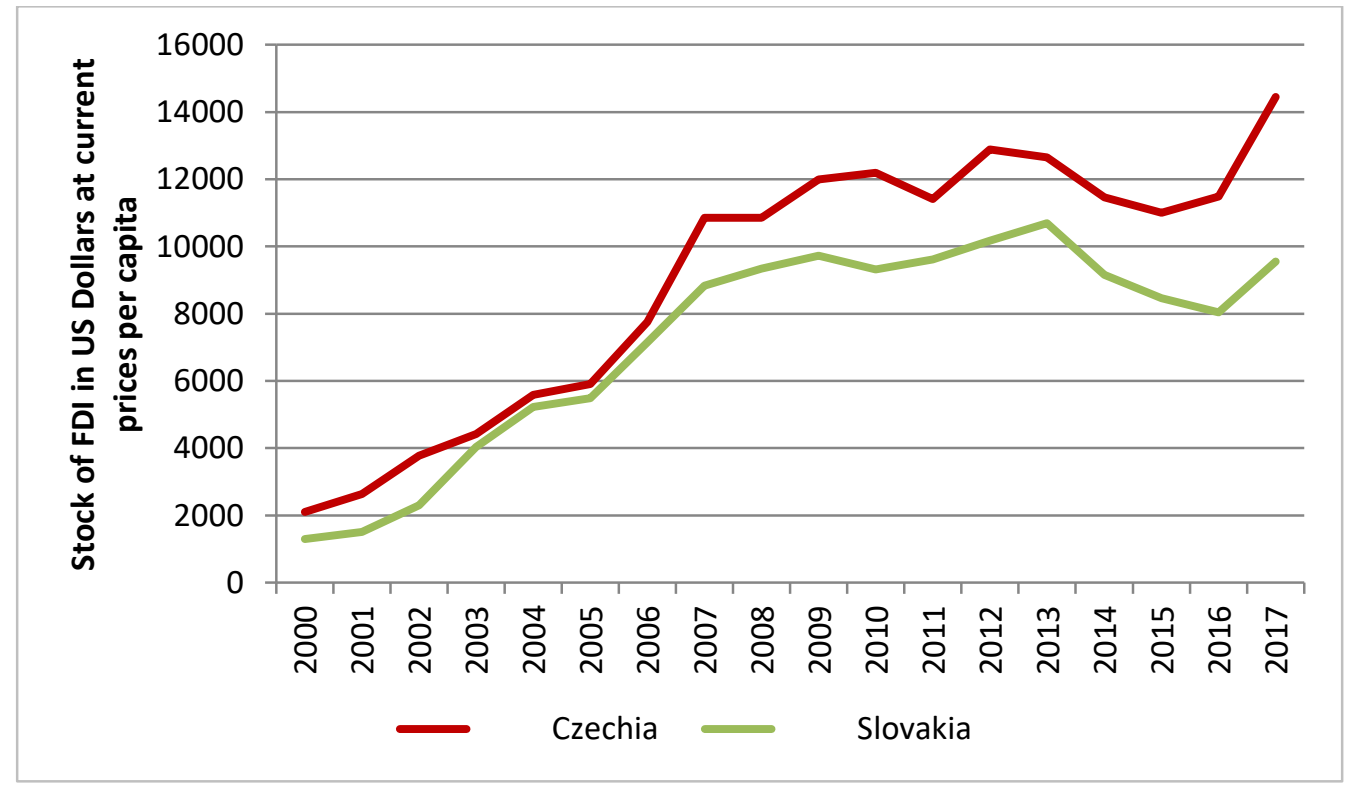

Figure 8. Czech Republic vs. Slovakia - FDI evolution

Source: Authors' calculations based on data provided by UNCTAD Stat 
We have also examined the dynamic of export for the NMS, in order to assess whether euro adoption had a significant effect over this macroeconomic variable. For this analysis we used a panel of nine countries, namely Czech Republic, Estonia, Latvia, Lithuania, Hungary, Poland, Romania, Slovenia and Slovakia. We noticed that all of them experienced a steady increase of exports during 2000-2017, when the average pace of exports growth was 20.7 percentage points annually. Nevertheless, this growth was not evenly distributed: there were some champions like Lithuania with 33.8\% increase per year, Slovakia with 32.2\% per year, and Romania with $26.9 \%$ per year, and then, on the other side, there several countries with moderate export increase were Hungary with only $12 \%$ per year and Slovenia with $13 \%$ per year. This positive trend was interrupted by the emergence of the financial in 2008-2009, as depicted by Figure 9.

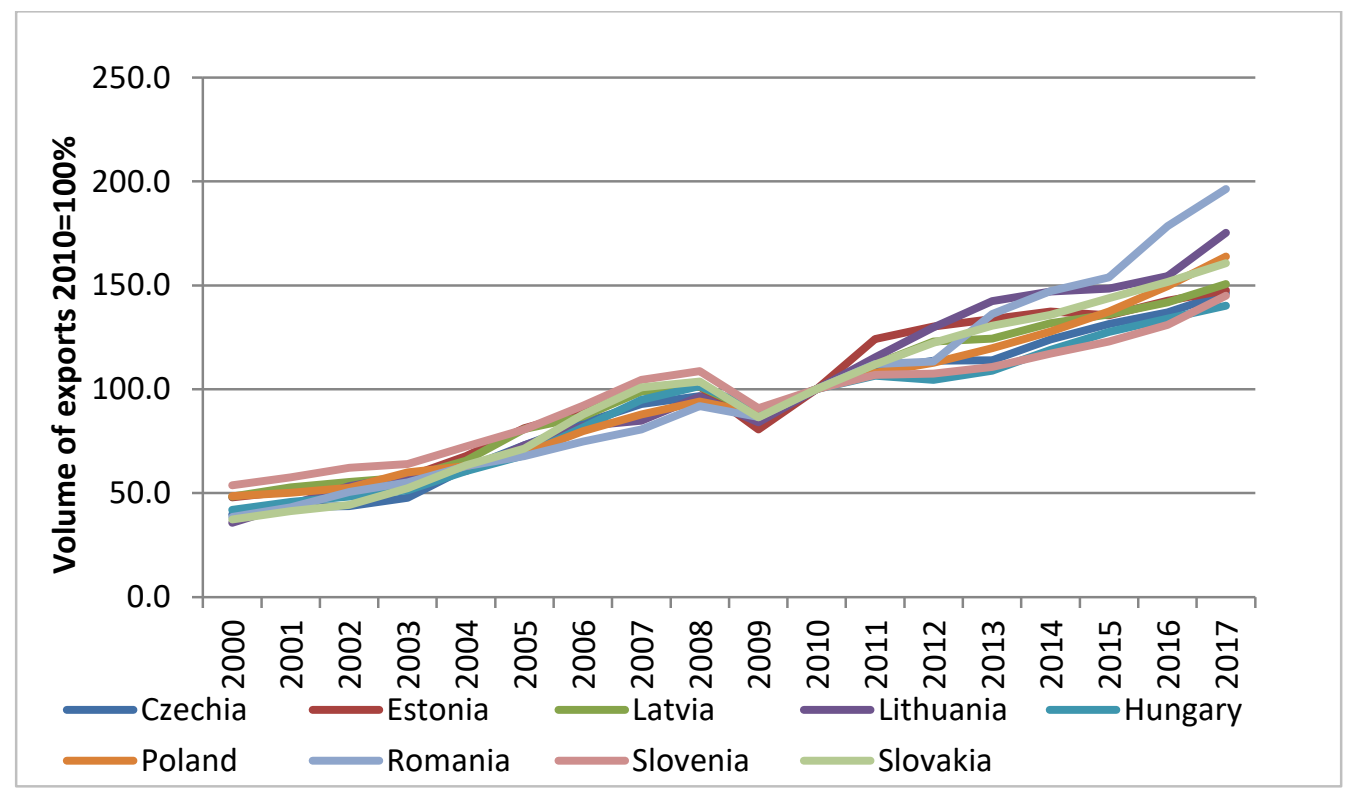

Figure 9. Evolution of export in the NMS

Source: Authors' calculations based on data provided by Eurostat

Therefore, the evolution of export in the NMS during the period 2000-2017 could be split in two: the flourishing period of 2000-2008, when all countries encountered highest growth of exports (the average increase being $21.3 \%$ per year), and the recovery period of 2009-2017, with moderate increase of exports (the average increase was only $10.4 \%$ per year).

During the first period (2000-2008), the champions with the highest pace of export growth were Slovakia (average increase of $37.5 \%$ per year), Lithuania (32\% per year) and Czech Republic (24\% per year), while during the second period (2009-2017) the top of exporting countries were Lithuania (16\% per year), Romania (15.44\% per year) and Poland (12.80\% per year). We noticed that Slovakia, who adopted the euro in 2009, registered a special evolution: while it had the highest pace of export growth during 2000-2008, well above the peers' average $(37,5 \%$ per year), Slovakia decelerated sharply during the 20092017 , slightly below the average of the group (10\% per year). It is important to mention that all Baltic countries had currency board arrangements and their national currencies had been 
anchored on the euro since 2005. Therefore, the effect of euro adoption on these countries was not expected to be significant from the export perspective.

Based on these mixed evolution, we concluded that there is no clear proof that Euro adoption has stimulated the exports dynamic.

Another significant indicator that we analyzed is foreign direct investments (FDI) that plays an essential role in transition economies.

PICBE $\mid 850$

We notice that the best performance in class is Estonia, where foreign investments burst out in 2003 to USD 5109 per capita. For instance, in the same year, Romania - the weakest performer - recorded a stock of FDI of only USD 562 per capita. But the strongest increase in FDI stock that pushed Estonia way ahead his peers was registered in 2012-2017.

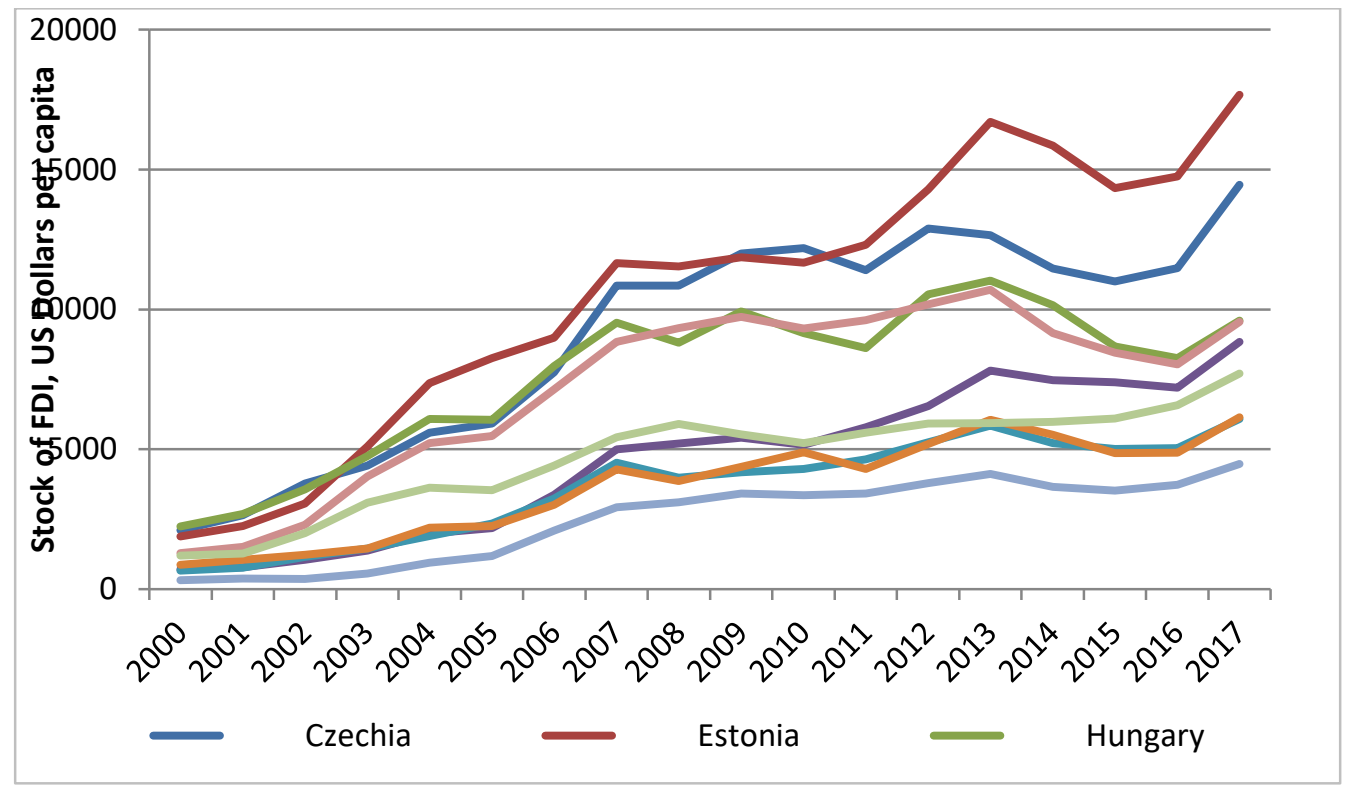

Figure 10. Evolution of FDI in the NMS

Source: Authors' calculations based on data provided by UNCTAD Stat

In order to see if there are any significant differences in terms of FDI evolution in NMS that adopted euro and those who did not, we eliminated outliers, namely Estonia and Romania. Therefore, we compared Slovenia, Slovakia, Latvia and Lithuania with the average of Czech Republic, Hungary and Poland. The Figure 11 shows that the average of non-euro countries systematically outperformed Slovenia, Latvia and Lithuania, closely following the FDI dynamic registered by Slovakia. We concluded that euro adoption did not prove to add any particular benefit to FDI evolution. 


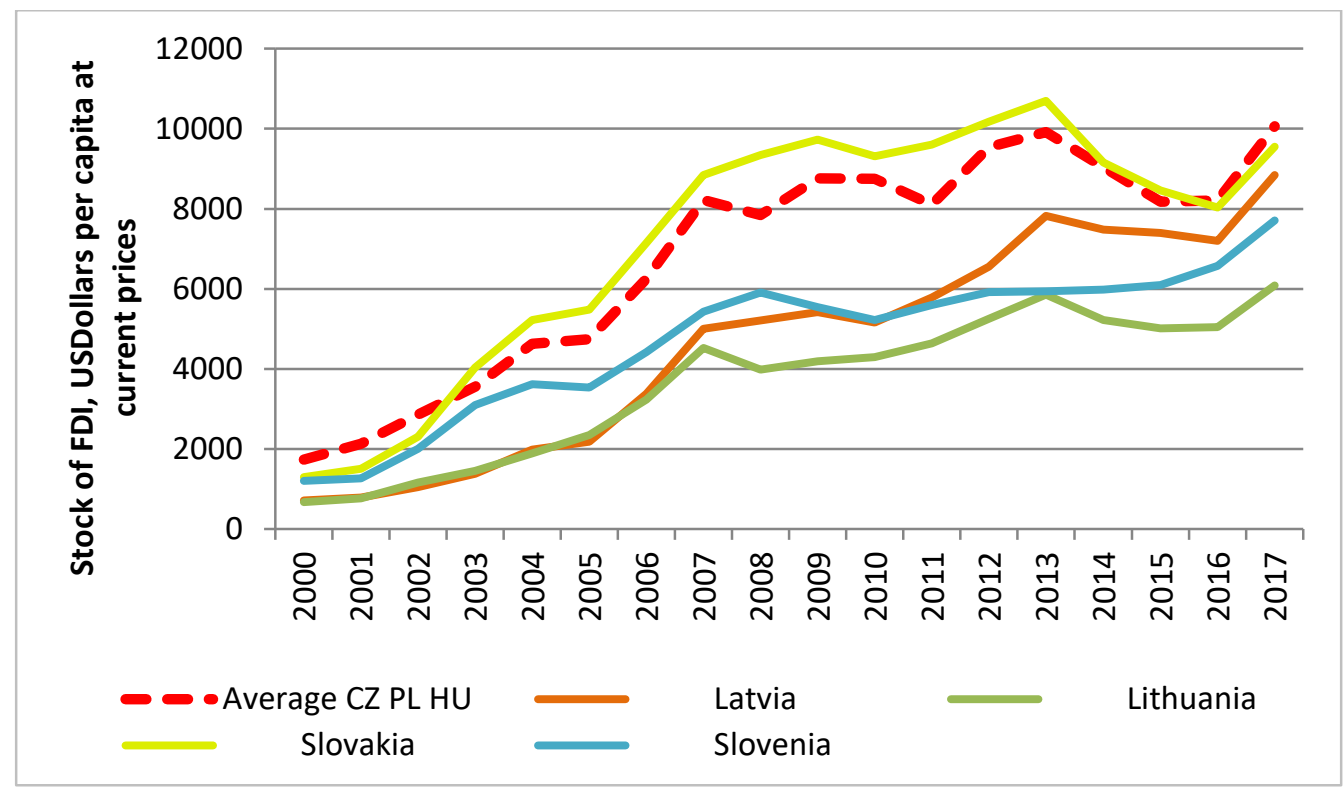

Figure 11. Evolution of FDI in selected NMS

Source: Authors' calculations based on data provided by UNCTAD Stat

\section{Conclusion}

In conclusion, the main purpose of this paper was to study if the Euro adoption guarantees an improvement of the economic indicators and busts the convergence process in the case of the NMS. Our study suggests that there is no hard evidence that Euro was a magic wand for the NMS. However, it seems that joining the EU and not necessarily the Euro adoption had a positive impact on the GDP growth of both Euro NMS and Non-Euro NMS. However, the NMS that already adopted Euro (Slovenia) or were about to enter in Eurozone (the Baltic Countries) were significant more affected by the economic and financial crisis that had the highest magnitude in Europe in 2009, in contrast with the Non-Euro NMS that stagnated (Bulgaria, Romania) or continued their growth (Poland).

The standard deviation and the coefficient of variation show that it is a high degree of convergence between the Euro NMS and also a downward trend in the case of Non-Euro NMS. In contrast, as far as the early adopters of the Euro are concerned, we observed a process of divergence that increased since 2000. Finally, it seems that the all the Euro NMS increased their economic performance in terms of GDP per capita and succeeded to reduce the discrepancies between them.

\section{References}

Artelaris, P., Kallioras, D. \& Petrakos, G. (2010.), Regional Inequalities and Convergence Clubs in the European Union New Member-States, Eastern Journal Of European Studies, Centre For European Studies, Alexandru Ioan Cuza University, 1 (1), 113-133. Auf dem Brinke, A., Henrik E. \& Joachim F. V. (2015). What kind of convergence does the Euro area need?, Gütersloh: Bertelsmann Stiftung und Jacques Delors Institut: Berlin. Retrieved from: https://www.delorsinstitut.de/2015/wpcontent/uploads/2015/12/Convergence-Study-Final.pdf. 
Barro, R. J. \& Sala-i-Martin, X. (1992). Convergence. Journal of Political Economy, Vol. 100(2), No. 2, pp 223-251. doi: https://doi.org/10.1086/261816.

Barro, R. J. (1991). Economic Growth in a Cross Section of Countries. The Quarterly Journal of Economics, 106 (2), 407-443. doi: 10.2307/2937943.

Baumol, W. (1986). Productivity Growth, Convergence, and Welfare: What the Long-Run Data Show. The American Economic Review, 76(5), 1072-1085 doi: 10.3386/w2419

PICBE $\mid 852$

Baumol, W. J., Nelson, R. R. \& Wolff, E. N. (1994), Introduction: The Convergence of Productivity, Its Significance, and Its Varied Connotations in Baumol, W. J., Nelson, R. R., Wolff, E. N (Eds.) Convergence of Productivity Cross-National Studies and Historical Evidence. USA: Oxford University Pres.

Beyaert, A., \& Camacho, M. (2008). TAR Panel Unit Root Tests and Real Convergence. Review of Development Economics, 12(3), 668-681.doi:10.1111/j.1467-9361.2008.00479.x.

Corrado, L., Martin, R., \& Weeks, M. (2005). Identifying and Interpreting Regional Convergence Clusters across Europe. The Economic Journal, 115(502), CC133-CC160. doi:10.1111/j.0013-0133.2005.00984.x.

Del Hoyo, J. J., Dorrucci, E., Heinz, F. F. \& Muzikarova, S. (2017). Real convergence in the euro area: a long-term perspective. European Central Bank. ECB Occasional Paper Series, 203. Frankfurt: European Central Bank. Retrieved from:

https://www.ecb.europa.eu/pub/pdf/scpops/ecb.op203.en.pdf?8ff80dd3a3b58f231 $105 f 3 e 4835 b 2928$.

Evans, P., Karras, G. (1996). Convergence revisited. Journal of Monetary Economics, 37(2), 249-265, doi: 10.1016/S0304-3932(96)90036-7.

Franks, J. \&Barkbu, B., Blavy, R., Oman, W. \& Schoelermann, H. (2018). Economic Convergence in the Euro Area: Coming Together or Drifting Apart? IMF Working Paper. International Monetary Fund: Washington. Retrieved from https://www.imf.org/en/Publications/WP/Issues/2018/01/23/EconomicConvergence-in-the-Euro-Area-Coming-Together-or-Drifting-Apart-45575.

Gaulier, G., Hurlin, C. \& Jean-Pierre, P. (1999) Testing Convergence: A Panel Data Approach. Annales d'Économie et de Statistique, 55/56, 411-427. doi: 10.2307/20076205.

Gros, D. (2018). Convergence in the European Union: Inside and outside the Euro. Centre for European Policy Studies. Retrieved from: https://www.ceps.eu/publications/convergence-european-union-inside-andoutside-euro.

Lucas, R., E. (1988). On the Mechanics of Economic Development. Journal of Monetary Economics, 22, (3-42). doi: 10.1016/0304-3932(88)90168-7.

Mankiw, G. Romer, D. \& Weil, D. A. (1992). A Contribution to the Empirics of Economic Growth. The Quarterly Journal of Economics, May, 407-437. doi: 10.3386/w3541.

Romer, P. M (1986). Increasing Returns and Long-Run Growth. The Journal of Political Economy, 94 (5), 1002-1037. doi: http://dx.doi.org/10.1086/261420.

van Loon, Y. (2018). Economic convergence as the cornerstone of EMU resilience Indicators, institutions and instruments. Clingendael Report. Netherlands:

Netherlands Institute of International Relations 'Clingendael'. Retrieved from: https://www.clingendael.org/sites/default/files/2018-

06/Report_Convergence_EMU-resilience.pdf. 
Wolff, E. (1991). Capital Formation and Productivity Convergence over the Long Term. American Economic Review, 81 (3), 565-79. Retrieved from: http://piketty.pse.ens.fr/files/Wolff1991.pdf

PICBE | 853 